\title{
Evaluation of Effectiveness of Three New Gingival Retraction Systems: A Comparative Study
}

\author{
Soni Kumari ${ }^{1}$, Purushottam Singh ${ }^{2}$, Umesh G Parmar ${ }^{3}$, Ankit M Patel $^{4}$
}

\begin{abstract}
Aim: To analyze the clinical effectiveness of three new gingival retraction systems: knitted retraction cord, expanding polyvinyl siloxane, and aluminium chloride containing paste.

Materials and methods: Twenty patients were enrolled with age-group of more than 18 years and who required fixed prosthesis with minimum of two abutments. A preliminary impression of the arch was made with a stock metal tray and irreversible hydrocolloid impression material. Group WR-impression without retraction, Group A-impression after retraction with gingival retraction cord, Group B-impression after retraction with expanding polyvinyl siloxane, and Group C-impression after retraction with aluminium chloride containing paste. A total of four impressions were made for each abutment tooth. Each impression was given a label 1WR, 1A, 1B, 1C-20WR, 20A, 20B, 20C: where 1 denoted the sample number. Comparison of the stereomicroscopic images was done using image analysis software. Time required from start of placement of gingival displacement agents till completion was recorded in seconds with the help of a stop clock.

Results: The mean gingival retraction was found to be the highest for subjects of Group C followed by Group A, Group B, and Group WR. This difference was found to be statistically significant. Highly significant mean difference in time of placement was observed between Group $A$ and Group B, between Group B and Group C, and between Group C and Group A.

Conclusion: The aluminium chloride containing paste was found effective in almost all the variables considered.

Clinical Significance: The choice of particular gingival retraction system/technique is dependent upon the clinical variables and on operator's preference.

Keywords: Expanding polyvinyl siloxane, Gingival retraction, Knitted retraction cord.

The Journal of Contemporary Dental Practice (2021): 10.5005/jp-journals-10024-3135
\end{abstract}

\section{InTRODUCTION}

In the era of modern dentistry, esthetics has become an integral component of treatment. Fixed prosthetic protocols in the esthetic areas unvaryingly encompass subgingival margins. Researches from the past literature have highlighted that subgingival margins are at higher risk of plaque accumulation in comparison to supragingival margins. Fixed partial dentures (FPDs) are routinely and effectively used for prosthetic rehabilitation of dentulous and partially edentulous patients. Synchronization between the prosthetic component and the periodontal tissue is vital. Technicality involved in framing of fixed prosthesis has continually been exaggerated in contrast to the clinical prospect. ${ }^{1-3}$

Oral cavity pretences many obstacles in the field of conservative dentistry from compelling impact of tongue and buccal mucosa to different hindrances of illumination, visual, and isolation while carrying out tooth preparatory procedures. The supposed "moisture control" is an indispensable component of any conservative dental procedure. It has been observed that the cavity contamination has a deleterious impact on the longevity of direct resin composite bond to tooth structure, specifically in patients in which there are persistent subgingival finish lines. Though by employing rubber dam delivers adequate control of the restoration part and access to the preparation, in most of the cases, its use is prohibited. Hence, substitute approaches of supervising moisture must be considered. ${ }^{4,5}$

Gingival displacement is a process which is done before making final impression. It reveals preparation's finish margins adequately. The impression method employed in the procedure of framing
${ }^{1}$ Department of Prosthodontics, Patna Dental College and Hospital, Patna, Bihar, India

${ }^{2}$ Department of Periodontics, Patna Dental College and Hospital, Patna, Bihar, India

${ }^{3}$ Private Consultant, Rajkot, Gujarat, India

${ }^{4}$ Private Practitioner, India

Corresponding Author: Soni Kumari, Department of Prosthodontics, Patna Dental College and Hospital, Patna, Bihar, India, e-mail: sonisaudansh@gmail.com

How to cite this article: Kumari S, Singh P, Parmar UG, et al. Evaluation of Effectiveness of Three New Gingival Retraction Systems: A Comparative Study. J Contemp Dent Pract 2021;22(8):922-927.

Source of support: Nil

Conflict of interest: None

fixed prostheses needs displacement of the gingival tissue for revealing the finish lines on final preparation of abutment. ${ }^{6-8}$ Hence, successful handling of the gingival tissue before impression making is a critical initial phase during fabricating restoration procedure. ${ }^{7,8}$ Knitted retraction cord is a rapid, simple, and cheaper technique but its utility is limited to supragingival preparation margins only. Expanding polyvinyl siloxane retraction system offers advantage of avoiding potentially traumatic and slower packing of retraction cord. However, its effectiveness has been reported to be lesser in comparison to different other retraction systems. Aluminium chloride falls under the category of hemostatic agent; hence,

(c) The Author(s). 2021 Open Access This article is distributed under the terms of the Creative Commons Attribution 4.0 International License (https://creativecommons. org/licenses/by-nc/4.0/), which permits unrestricted use, distribution, and non-commercial reproduction in any medium, provided you give appropriate credit to the original author(s) and the source, provide a link to the Creative Commons license, and indicate if changes were made. The Creative Commons Public Domain Dedication waiver (http://creativecommons.org/publicdomain/zero/1.0/) applies to the data made available in this article, unless otherwise stated. 
it prevents iatrogenic injury to gingival tissues. They also have astringent effect. However, their efficacy is limited in pockets which are deeper than $2 \mathrm{~mm}^{7-9}$ There is paucity of data in the literature comparing the effectiveness of these three gingival retraction systems. This study aims at comparative evaluation of gingival displacement obtained using the following retraction systems: knitted retraction cord, expanding polyvinyl siloxane, and aluminium chloride containing paste, taking depth and width of gingival sulcus as the parameters.

\section{Materials and Methods}

In the present study, twenty patients were enrolled with age-group of more than 18 years and who required fixed prosthesis with minimum of two abutments. Abutment teeth with sound gingival and periodontal health were included. Subjects with the presence of gingival and periodontal diseases were excluded. Ethical approval was obtained from ethical committee of the institution. Informed consent was also obtained from all the patients before commencing the study. The sample size was calculated using the formula $N=(Z 1-a / 2+Z 1-\beta) 2$, where $Z-a / 2$ is the standard normal deviate at type 1 error $\alpha=0.05$.

\section{Clinical Procedure: Custom Tray Fabrication}

A preliminary impression of the arch was made with a stock metal tray and irreversible hydrocolloid impression material. Dental stone models retrieved from these impressions were used to fabricate custom acrylic trays with a double sheet modeling wax spacer. On the tray, perforations were created. The tray included one tooth on either side of the abutment teeth. A total of four trays were made for each sample.

\section{Gingival Retraction and Impression Making}

The abutment tooth was prepared for full coverage crown with an equigingival finish line. After few days - the baseline impression was made, impressions were made after displacement with one of the three displacement agents.

\section{Gingival Displacement and Impression Making}

The time interval for displacing the gingival tissue and for making an impression followed a Latin block design.

On day 1, the baseline impression was made. On day 2, day 3 , and day 4, impressions were taken after displacement with anyone of the three displacement agents.

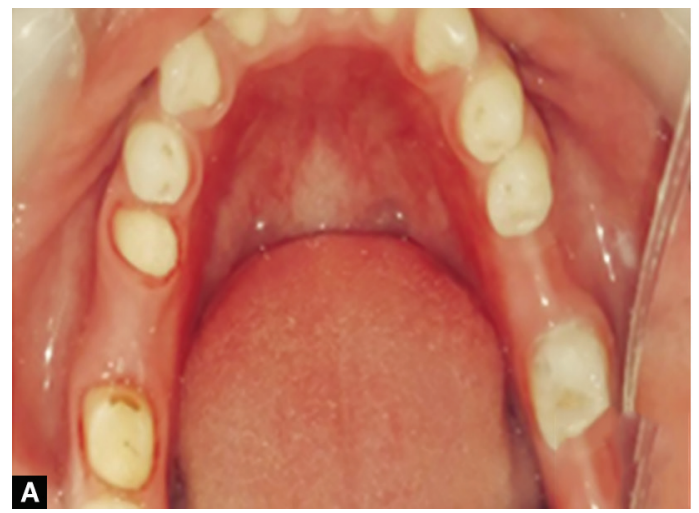

Figs $1 \mathrm{~A}$ and $\mathrm{B}$ : (A) No retraction and (B) Impression without retraction

\section{Baseline Impression}

In the control group, baseline impressions were taken. Afterward, a second impression was taken after taking away the spacer.

\section{Gingival Retraction Using Cord and Impression}

Isolation of the tooth with cotton rolls was done. Retraction cord was looped around the tooth. Packing was started from the mesial interproximal area by gently pushing it into the sulcus with the gingival cord packer instrument (Hu Friedy) using the single cord technique. Retraction cord was kept in place for 10 minutes. An impression using putty consistency PVS and cellophane sheet spacer was made, cord was removed, and impression relined with light-body consistency PVS.

\section{Expanding Polyvinyl Siloxane Retraction and Impression}

Expanding polyvinyl siloxane was available in cartridges which were automixed using syringe tips and applied into the gingival sulcus using oral tips. Anatomic comprecaps preselected according to the size of the tooth were placed over it and patient was instructed to close mouth under bite pressure. Magic foam cord was left in place for 5 minutes according to the manufacturer's instructions and impression was made similar to baseline impression.

\section{Aluminium Chloride Containing Paste Retraction and Impression}

Aluminium chloride containing paste was injected slowly into the sulcus. After 2 minutes, aluminium chloride containing paste was washed away from sulcus using air and water spray. Impression was made in similar way as baseline impression.

\section{Groups}

- Group WR-impression without retraction (Fig. 1)

- Group A-impression after retraction with gingival retraction cord (Fig. 2)

- Group B-impression after retraction with expanding polyvinyl siloxane (Fig. 3)

- Group C-impression after retraction with aluminium chloride containing paste (Fig. 4)

A total of four impressions were made for each abutment tooth. Each impression was given a label 1WR, 1A, 1B, 1C-20WR, 20A, 20B, 20C: where 1 denoted the sample number. 

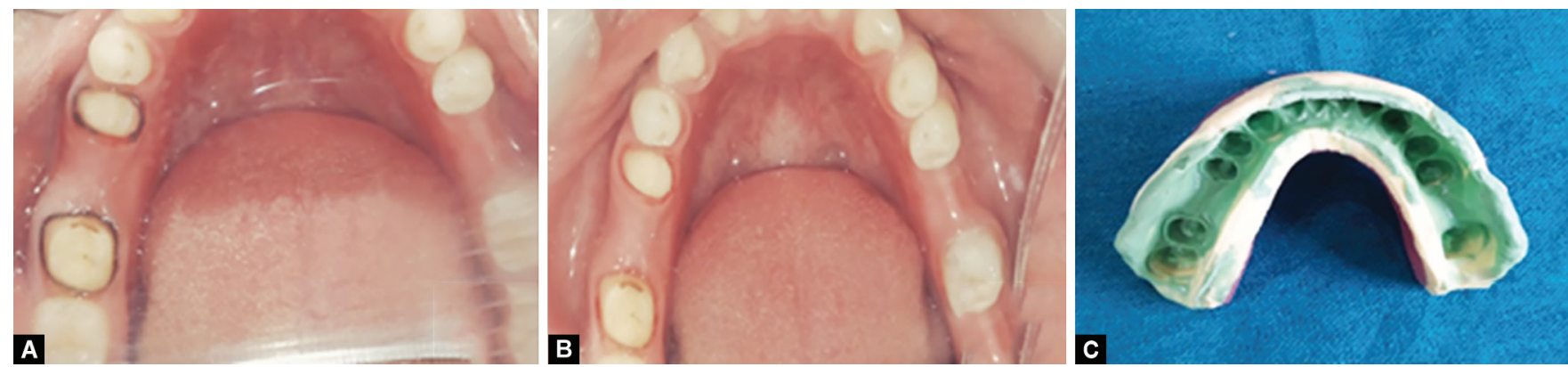

Figs 2 A to C: (A) Knitted retraction cord placement; (B) Knitted retraction cord removed; and (C) Impression after removing knitted retraction cord
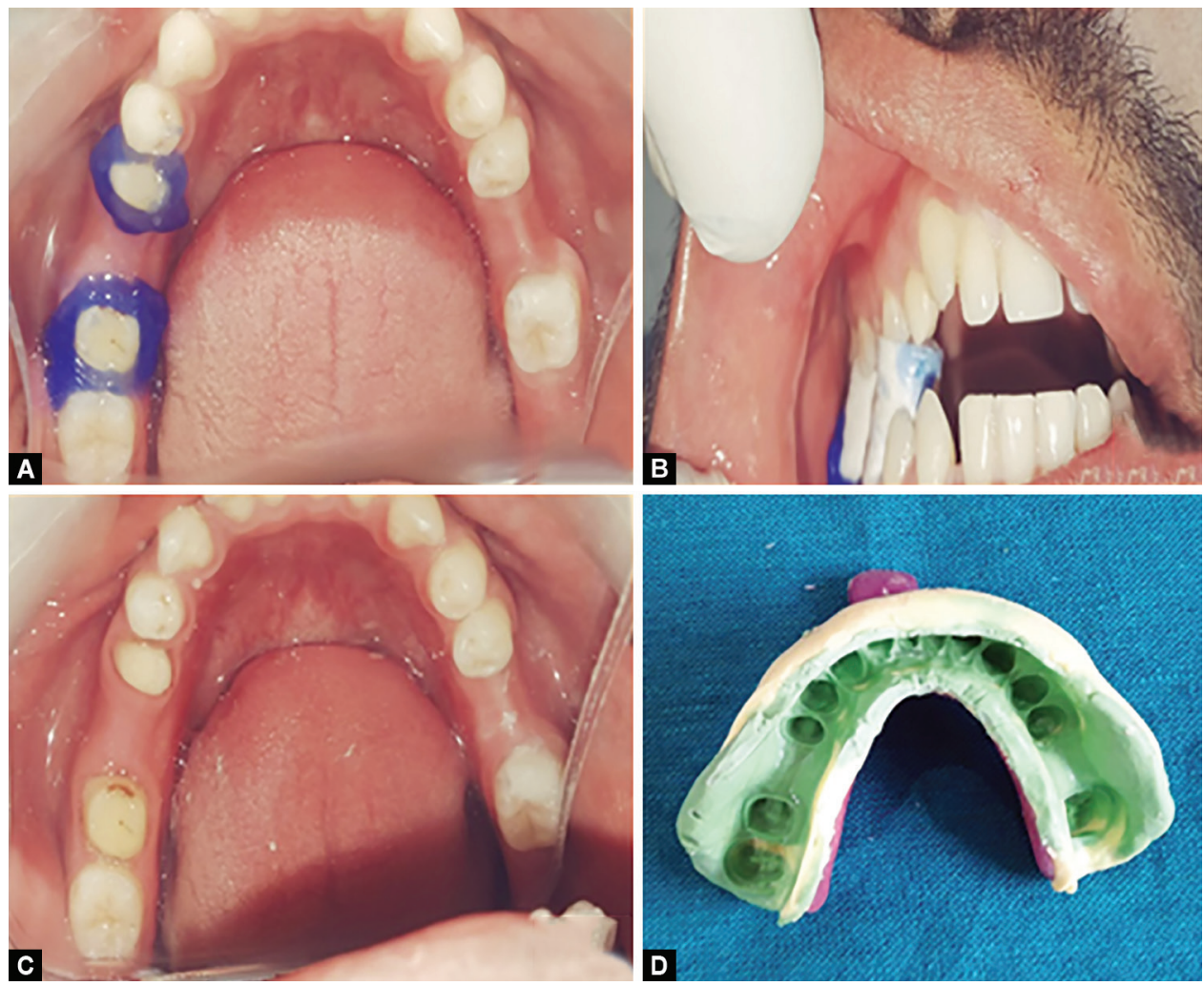

Figs 3A to D: (A) Expanding polyvinyl siloxane placement; (B) Comprecap under bite pressure; (C) Expanding polyvinyl siloxane removed; and (D) Impression after removing expanding polyvinyl siloxane
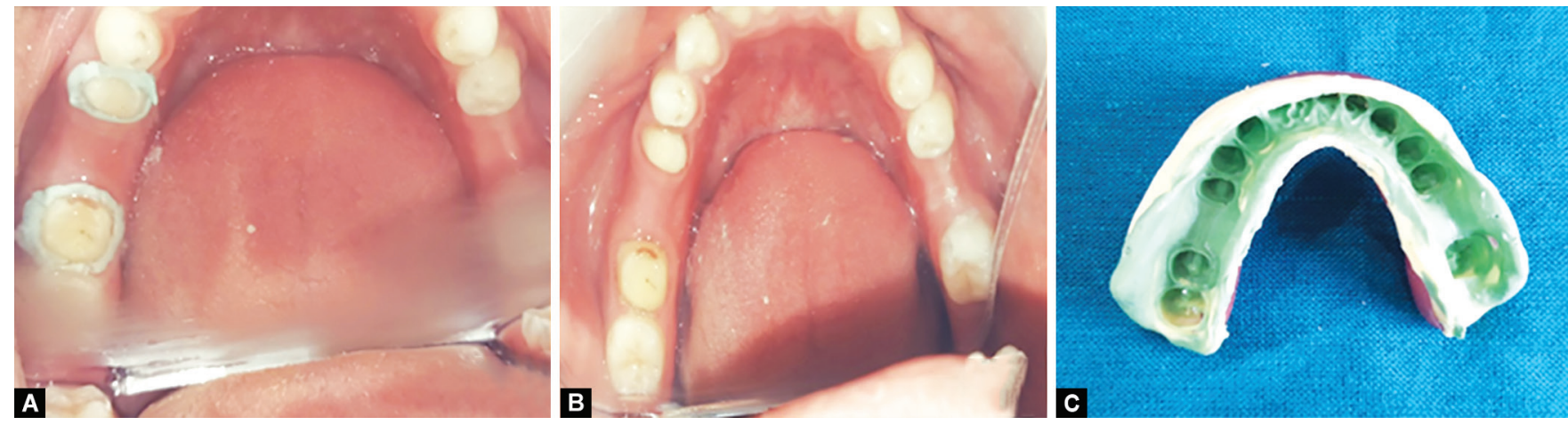

Figs 4A to C: (A) Aluminium chloride containing paste placement; (B) Aluminium chloride containing paste removed; and (C) Impression after removing aluminium chloride containing paste 


\section{Evaluation of Samples for Gingival Retraction}

The stereomicroscopic evaluation of abutment teeth singly on polyvinyl siloxane impressions made before retraction and after retraction was compared using image analysis software (Fig. 5).

\section{Time Required for Application}

Time required from start of placement of gingival displacement agents till completion was recorded in seconds with the help of a stop clock. Each agent was placed after a few days interval. All the results were recorded in Microsoft excel sheet and were subjected to statistical analysis using SPSS software version 16.0. Tukey's test and one-way ANOVA were used for the evaluation of level of significance.

\section{Results}

The mean gingival retraction was found to be the highest for subjects of Group C ( $0.43 \pm 0.09)$ followed by Group A, Group B, and Group WR (Table 1); the comparative results were found to be significant. Mean time required for application among Group A, Group B, and Group C was 160.8, 139.45, and 27.5 seconds, respectively (Fig. 6). Individual comparison with Tukey's post hoc test revealed highly significant mean difference in time of placement between Group A and Group B ( $p=0.0001)$, between Group B and Group C ( $p=0.0001)$, and between Group C and Group A $(p=0.002)$ (Table 2$)$.

\section{Discussion}

There is paucity of data in literature in relation to the clinical effectiveness with gingival retraction materials. Ultrapak retraction cord has chain-like construction of interlocking loops. Reliability of the cod whether it is twined or knitted is more significant in comparison to the type of medicament used. ${ }^{6,7}$ Along with this, the cord's saturation with the solutions is highly dependent upon the wetting of the cords. ${ }^{7-9}$ In the current research, cord was soaked in saline solution to enhance the mechanical effect and 20 minutes of soaking time was necessary for the saturation of the cords before use, provided that air trapped within the cords was removed.

Adequate handling and supervision of the gingival sulcus are required for successful subgingival impression. It encompasses two key variables: the amount of force to which gingival tissues are subjects; and contaminants that might exist in that vicinity. ${ }^{7-10}$ The accomplishment and marginal integrity of any prosthetic component are largely dependent upon precision of their margins. Precise adaptation of prosthetic component to finish line is must for diminishing the cement dissolution and for preserving the periodontium in FPD cases. This is likely to occur only when abutment particulars are taken accurately in the impression and precisely transferred to the cast. Because of these causes, gingival displacement is must to capture subgingival preparation specifics. $^{10-12}$

Gingival retraction is required for appropriate lateral displacement of gingiva, for satisfactory movement of impression material and for precise recording of prepared finish line. At the same time, it also renders easy removal of excess cementum during cementation process. ${ }^{12-14}$ Expasyl has been formulated for dealing with impressions, prosthetic component seating, rubber dam insertion, and restoration of cavity difficulties, saving significant proportion of time for the clinician and improving patient's comfort. ${ }^{12-15}$ Hence, the present study was undertaken
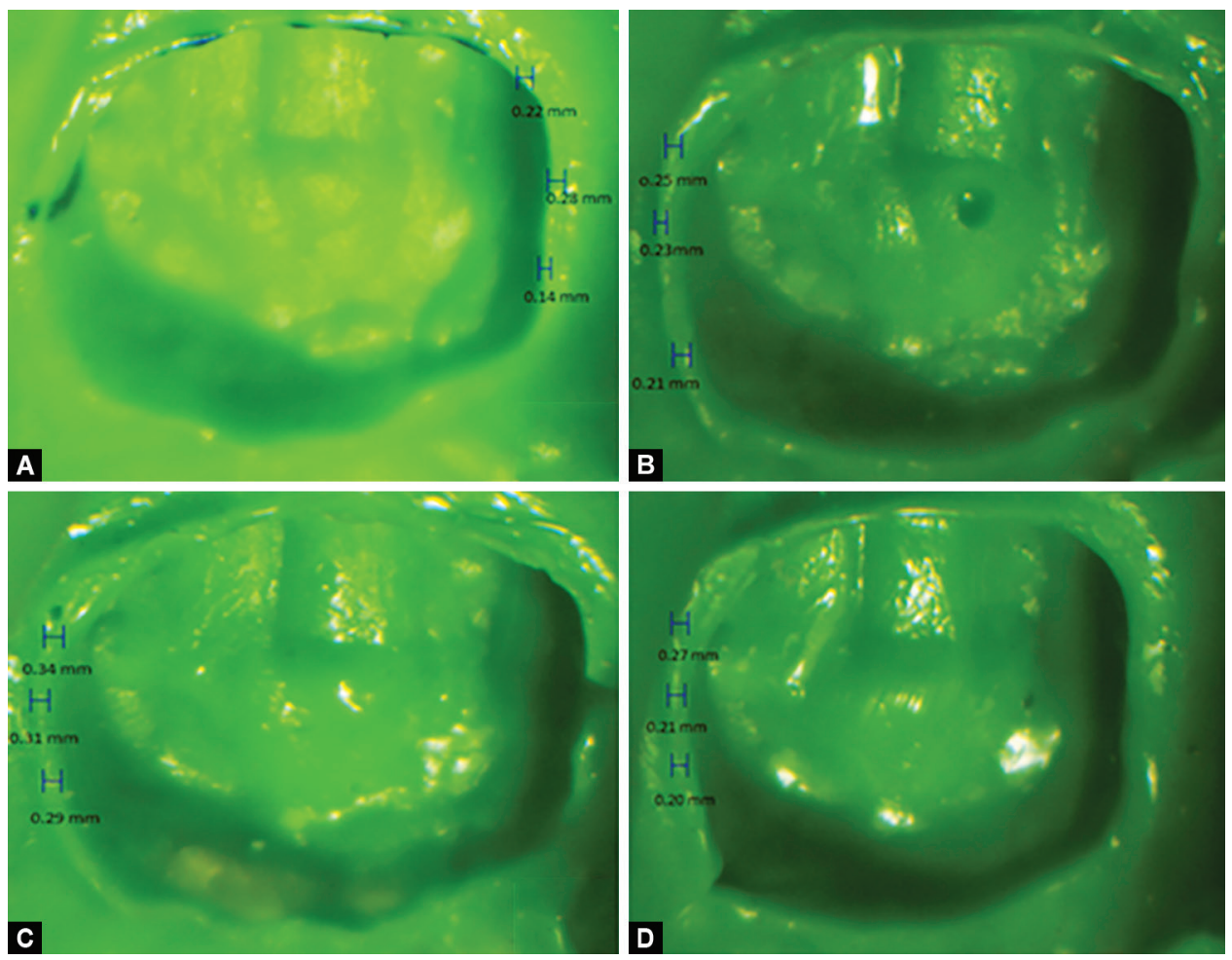

Figs 5A to D: (A) Image analysis of impression made before retraction; (B) Image analysis of impression made after using retraction cord; (C) Image analysis of impression made after using aluminium chloride containing paste; and (D) Image analysis of impression made after using expanding polyvinyl siloxane 
Table 1: One-way ANOVA for gingival retraction

\begin{tabular}{lcc}
\hline Groups & Retraction (mean \pm SD) & pvalue \\
\hline Group WR & $0.25 \pm 0.07$ & \\
Group A & $0.36 \pm 0.11$ & 0.0001 \\
Group B & $0.33 \pm 0.08$ & \\
Group C & $0.43 \pm 0.09$ & \\
\hline
\end{tabular}

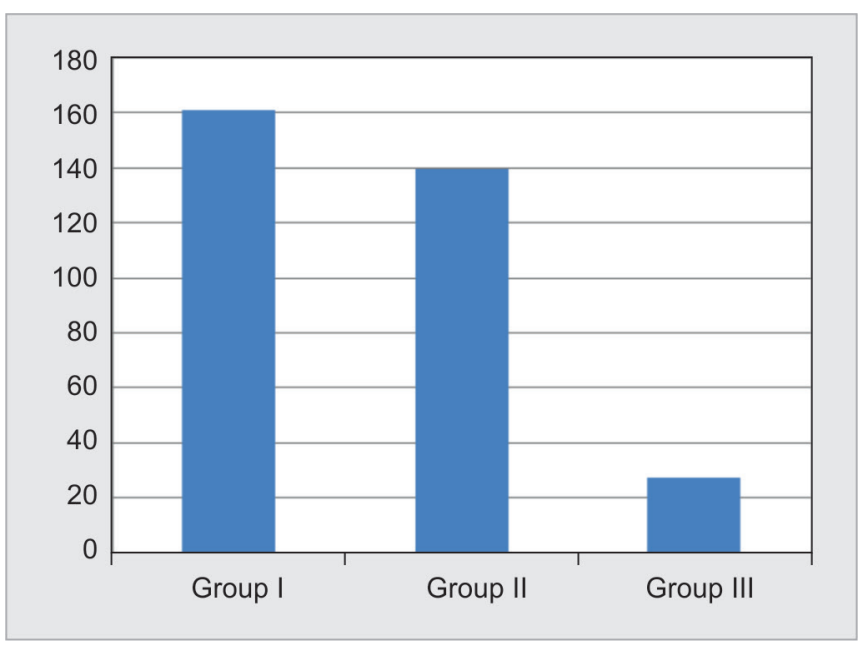

Fig. 6: Mean time required for application (seconds)

Table 2: Tukey's test for individual comparison between groups

\begin{tabular}{lccc}
\hline Groups & $A$ & $B$ & $C$ \\
\hline A & - & 0.0001 (significant) & 0.002 (significant) \\
B & 0.0001 (significant) & - & 0.0001 (significant) \\
C & 0.002 (significant) & 0.0001 (significant) & - \\
\hline
\end{tabular}

for comparative evaluating gingival displacement obtained using the following retraction systems: knitted retraction cord, expanding polyvinyl siloxane, and aluminium chloride containing paste, taking depth and width of gingival sulcus as the parameters.

In the present study, the mean gingival retraction was found to be the highest for subjects of Group C followed by Group A, Group B, and Group WR. This difference was found to be statistically significant. Both the retraction materials produced sulcus width of $>0.2 \mathrm{~mm}$, but the amount of retraction produced by both of these materials was almost similar. Our results were in concordance with the results obtained by Mehta et al., who also observed similar findings. In their research, authors assessed and compared the effectiveness of three gingival retraction systems in root canaltreated teeth. They analyzed 45 subjects and broadly divided into three study groups depending upon the type of retraction cord used. Their results did not demonstrated significant effectiveness of that the new retraction systems in comparison to the usual retraction cords. ${ }^{14}$

Knitted retraction cord works on the principle of mechanical displacement of gingival tissue. The technicality involved includes manual movement of the gingival tissue by positioning inside the sulcus to attain enhanced retraction of gingival tissue. The expanding polyvinyl siloxane was possibly less distressing since meticulous pressure was employed, whereas minimal trauma occurred with aluminium chloride as it induced no bleeding. ${ }^{12-15}$

In the present study, mean time required for application among Group A, Group B, and Group C was 160.8, 139.45, and 27.5 seconds, respectively. In a previous study conducted by Gupta et al., authors compared the clinical effectiveness of three new gingival retraction systems: stay-put, magic foam cord, and expasyl. The authors concluded that the magic foam cord retraction system could be regarded as more effective gingival retraction system in comparison to others. ${ }^{15}$ Studies have evaluated the clinical success of "Expasyl" as an alternative to conventional retraction cord using the matrix impression system (MIS) with the aid of a stereomicroscope. ${ }^{14-16}$

In the present study, Latin block design was employed in sequence of gingival displacement to overcome the tissue fatigue. Normally, the amount of displacement produced during the first retraction would be expected to be the least when compared to the last retraction or vice versa. This would mean that the first agent and the last agent may give results that are not true to their chemistry but by virtue of the amount of tissue fatigue that occurs during the procedure of displacement. Latin block design delivers equivalent probability for each agent to be placed at a differential order of treatment; hence, it is employed in this study. In another study conducted by Qureshi et al., authors compared the effectiveness of different gingival displacement materials in achieving gingival tissue displacement. From the results, they concluded that the astringent gingival retraction paste demonstrated maximum gingival displacement. ${ }^{16,17}$

\section{Conclusion}

The aluminium chloride containing paste was found to be efficacious in all the parameters included in the current research. Also, the optimal gingival retraction apparatus is still determined by clinical environment and on clinician's preference.

\section{Limitation of the Study}

Same patients were called for the impression procedure four times, which was quite cumbersome and could have caused alteration of the results. We could not find any other method to circumvent this.

\section{References}

1. Donovan T, Chee W. Current concepts in gingival displacement. Dent Clin North Am 2004;48(2):433-444. DOI: 10.1016/j.cden.2003.12.012.

2. Raja Z, Nair C. A clinical study on gingival retraction. J Indian Prosthodont Soc 2003;3(3):21-27.

3. Glantz P, Nyman S. Technical and biophysical aspects of fixed partial dentures for patients with reduced periodontal support. J Prosthet Dent 1982;47(1):47-51. DOI: 10.1016/0022-3913(82)90241-4.

4. Holmes H. Gingival displacement, not retraction. Dent Surv 1968;44(12):35-36.

5. Nemetz $\mathrm{H}$. Tissue management in fixed prosthodontics. J Prosthet Dent 1974;31(6):628-636. DOI: 10.1016/0022-3913(74)90117-6.

6. Laufer B, Baharav H, Ganor Y, et al. The effect of marginal thickness on the distortion of different impression materials. J Prosthet Dent 1996;76(5):466-471. DOI: 10.1016/s0022-3913(96)90002-5.

7. Klug RG. Gingival tissue regeneration following electrical retraction. J Prosthet Dent 1966;16(5):955-962. DOI: 10.1016/0022-3913(66) 90018-7.

8. Livaditis G. The matrix impression system for fixed prosthodontics. J Prosthet Dent 1998;79(2):208-216. DOI: 10.1016/s0022-3913(98) 70217-3. 
9. Shillingburg $H T$, Hobo $S$, Whittsett $L D$, et al. Fundamentals of fixed prosthodontics (3rd ed) Chicago, IL. Quintessence Int 1997;3:257-259.

10. Ferrari M, Cagidiaco M, Ercoli C. Tissue management with a new gingival retraction material: a preliminary clinical report. J Prosthet Dent 1996;75(3):242-247. DOI: 10.1016/s0022-3913(96)90479-5.

11. Cimma R, Cravero M, Farina G, et al. Tissue management with the Nd:YAG laser: a clinical report. J Oral Laser Appl 2007;7(2):107-113.

12. Harrison J. Effect of retraction materials on the gingival sulcus epithelium. J Prosthet Dent 1961;11(3):514-521. DOI: 10.1016/00223913(61)90234-7.

13. Loe $H$, Odont $D$, Silness J. Tissue reactions to string packs used in fixed prosthodontics. J Prosthet Dent 1963;13(2):318-323.

14. Mehta S, Virani H, Memon S, et al. A comparative evaluation of efficacy of gingival retraction using polyvinyl siloxane foam retraction system, vinyl polysiloxane paste retraction system, and copper wire reinforced retraction cord in endodontically treated teeth: an in vivo study. Contemp Clin Dent 2019;10(3):428-432. DOI: 10.4103/ ccd.ccd_708_18.

15. Gupta A, Prithviraj DR, Gupta D, et al. Clinical evaluation of three new gingival retraction systems: a research report. J Indian Prosthodont Soc 2013;13(1):36-42. DOI: 10.1007/s13191-012-0140-y.

16. Raghav D, Singh S, Kola $M$, et al. A comparative clinical and quantitative evaluation of the efficacy of conventional and recent gingival retraction systems: an in vitro study. Eur J Prosthodont 2014;2(3):76-81. DOI: 10.4103/2347-4610.140514.

17. Qureshi SM, Anasane NS, Kakade D. Comparative evaluation of the amount of gingival displacement using three recent gingival retraction systems-in vivo study. Contemp Clin Dent 2020;11(1):28-33. DOI: 10.4103/ccd.ccd_311_19. 